\title{
Labelling of cells of the mononuclear phagocyte system in routinely processed archival biopsy specimens with monoclonal antibody EBM/11
}

\author{
G I N Greywoode, S P McCarthy, J O'D McGee
}

\begin{abstract}
When first reported, $E B M / 11$ reacted with mononuclear phagocyte system cells only in fresh frozen sections, but it has been shown to have similar cellular specificity in routine formalin fixed, paraffin wax embedded tissue. This was achieved by limited proteolysis with protease XIV before immunocytochemical staining. In archival biopsy specimens EBM/11 produced granular cytoplasmic staining of alveolar macrophages, Kupffer cells, tingible body macrophages and sinus histiocytes, cells of splenic cords, cortical and medullary macrophages of thymus; blood monocytes, peritoneal and mesothelial macrophages; bone marrow mononuclear cells, megakaryocytes and osteoclasts; lamina propria macrophages in the gastrointestinal tract, and connective tissue cells (presumptive macrophages) of thyroid, gall bladder, skin, pancreas, ovary, myometrium, endometrium, cervix, kidney, prostate, placenta, myocardium and breast. Unlike other anti-macrophage antibodies, EBM/11 did not react with granulocytes, lymphocytes, plasma cells, platelets, endothelial and epithelial cells in paraffin wax sections. It did not label skin Langerhans' cells, microglial cells, and interdigitating reticulum cells (as in frozen sections).

This study opens a new area for the specific identification by $E B M / 11$ of mononuclear phagocyte system cells in archival biopsy specimens. It also raises the possibility that some monoclonal antibodies, believed to be reactive only in frozen sections, may react in archival tissue after limited proteolysis with an appropriate enzyme.
\end{abstract}

There is considerable interest in the origin, differentiation, and functions of the cells of the mononuclear phagocyte system. This is evident from the diverse histochemical and immunocytochemical criteria for their identification. It is generally accepted that monocytes and granulocytes are derived from the same committed precursor cells-that is, myelomonoblasts of bone marrow. The stimulus and the sensory mechanisms controlling these cells to differentiate into monocytes or granulocytes are unclear, as is the stimulus for migration of circulating mono- cytes into tissue to evolve into specialised cells of the mononuclear phagocyte system. Functionally, cells of the mononuclear phagocyte system can be broadly grouped into antigen presenting, immunostimulating, phagocytic, secretory and cytolytic cells. These cells act in concert with other cells, such as lymphocytes and granulocytes, in many pathological processes. For specific investigation of mononuclear phagocyte system cells in disease processes it is clear that they should be selectively distinguished from other cells.

Some monoclonal antibodies react with cytoplasmic determinants of macrophages in routinely processed tissues. Many are unsuitable for specific tissue identification of macrophages; and other cells of the mononuclear phagocyte system, because they recognise epitopes shared by other cells-for example, lymphocytes, granulocytes, and epithelial cells. ${ }^{1-5} \mathrm{EBM} / 11$, a monoclonal antibody in the CD68 group, shows high cellular specificity for mononuclear phagocyte system cells in fresh cell suspensions, imprints, and frozen sections. ${ }^{6-11}$ We report that in normal and diseased tissues EBM/11 selectively stains cytoplasm of mononuclear phagocyte system cells in formaldehyde-fixed, routinely processed tissues after limited proteolysis with protease XIV.

\section{Methods}

TISSUE SAMPLES AND FIXATION

Routinely processed surgical biopsy specimens were obtained from the block file (1980-89) of this department. These included two randomly selected blocks from morphologically normal tissues (table 1). Archival blocks from some granulomatous reactions containing epitheloid macrophages; multi-nucleated giant cells and foamy macrophages were also investigated. All tissues were fixed in unbuffered formolsaline-that is, $10 \%(\mathrm{v} / \mathrm{v})$ formaldehyde and $0.9 \%(\mathrm{w} / \mathrm{v})$ sodium chloride stored over marble chips. Fixation time varied from five to 72 hours.

The effects of fixation time and $\mathrm{pH}$ on the detectability of the EBM/11 epitope were investigated using necropsy tissue fixed in the following solutions: unbuffered formol-saline (see above); acetic acid/formol-saline (formolsaline adjusted to $\mathrm{pH} 2.0$ with concentrated glacial acetic acid); buffered formalin, $\mathrm{pH} 7 \cdot 2$, ( $10 \%$ formaldehyde containing $0 \cdot 2 \mathrm{M}$ disodium hydrogen orthophosphate/sodium dihydrogen orthophosphate); buffered formalin, $\mathrm{pH} \mathbf{8} \cdot 4$, ( $10 \%$ formaldehyde containing $0 \cdot 2 \mathrm{M}$ disodium 
Table $1 E B M / 11$ reactive cells in normal, routinely processed archival biopsy specimens

\begin{tabular}{ll}
\hline Tissue & Reactive cell type \\
\hline Liver & Kupffer cell and portal tract macrophages \\
Spleen & Phagocytic cells of splenic cords and tingible body macrophages \\
Thymus & of reactive white pulp \\
Lymph node & Cortical and medullary macrophages \\
Tonsil & Sinus, mantle zone and tingible body macrophages \\
Bone marrow & Interfollicular and germinal centre macrophages \\
Small bowel/large bowel/gall bladder & Osteoclasts, megakaryocytes, and mononuclear cells \\
Skin & Mucosal and interstitial macrophages \\
Brain & Dermal macrophages \\
Heart/kidney & Perivascular macrophages \\
Endometrium/cervix/myometrium & Interstitial macrophages \\
Placenta & Interstitial macrophages \\
Ovary/testis/breast/prostate/thyroid & Chorionic villi macrophages \\
\hline
\end{tabular}

hydrogen orthophosphate/sodium dihydrogen orthophosphate). Fixation times ranged from six to 168 hours. A few tissues that had been stored in buffered formalin, $\mathrm{pH} 7 \cdot 2$, for one year were also investigated. Blocks $(10 \mathrm{~mm} \times$ $20 \mathrm{~mm} \times 5 \mathrm{~mm}$ and $10 \mathrm{~mm} \times 5 \mathrm{~mm} \times 5 \mathrm{~mm}$ ) of liver, spleen, lymph node, bowel, brain and lungs were used in the experiments on necropsy tissue.

\section{IMMUNOHISTOCHEMISTRY}

Sections $(4 \mu \mathrm{m})$ were heated at $60^{\circ} \mathrm{C}$ for five minutes and dewaxed in xylene twice for three minutes, and rehydrated in two changes of $98 \%$ and $70 \%$ industrial ethanol, distilled water, and TRIS-buffered-saline (TBS), $\mathrm{pH}$ $7 \cdot 2$ (three minutes each change). Sections were digested with $2 \%(\mathrm{w} / \mathrm{v})$ protease from Streptomyces griseus Type XIV (Sigma) at $22^{\circ} \mathrm{C}$ for 15 minutes and washed in distilled water and TBS; each wash lasted two minutes. To block non-specific staining sections were immersed in TBS containing $5 \%$ bovine serum albumin and $0 \cdot 1 \%$ Triton-X-100 (TBT) for five minutes. TBT was decanted and the EBM/11 epitope visualised by the APAAP method. ${ }^{12}{ }^{13}$ Briefly, sections were sequentially incubated at $22^{\circ} \mathrm{C}$ with monoclonal antibody $\mathrm{EBM} / 11$ (neat culture supernatant), rabbit anti-mouse immunoglobulin (Dako UK; diluted 1 in 50 in TBS containing $5 \%$ bovine serum albumin) and alkaline phosphatase antialkaline phosphatase (Dako UK) complex (diluted 1 in 100 in TBS containing $5 \%$ bovine serum albumin). Incubation with the latter two reagents was repeated once. Each incubation step in these protocols were followed by a three minute wash in TBS. Sites of reactivity of $\mathrm{EBM} / 11$ were detected with $0.02 \%(\mathrm{w} / \mathrm{v})$ naphthol AS-MX phosphate-free acid, $2 \%$ (v/v) dimethylformamide, and $0 \cdot 1 \%(w / v)$ Fast Red TR salt in $0 \cdot 1 \mathrm{M}$ TRIS buffer (pH 8.2); $0.03 \%(w / v)$ levamisole was added to inhibit endogenous alkaline peroxidase. All the reagents in the detection system were supplied by Sigma UK. Sections were counterstained with Mayer's haematoxylin and mounted in an aqueous medium. Some sections were also strained by the two-stage immunoperoxidase technique $^{1314}$ and mounted in DPX. Negative controls included substituting $\mathrm{EBM} / 11$ (on adjacent sections) with normal culture medium or an irrelevant monoclonal antibody $\mathrm{JMB}^{15}$; in positive controls EBM/11 was replaced by a cocktail of epithelial monoclonal antibodies.

\section{Results}

EBM/11 produced granular cytoplasmic staining of alveolar and interstitial macrophages of lung (fig 1), Kupffer cells and macrophages within portal tracts of liver (fig 2), and in subcapsular, mantle zone, paracortical and tingible body macrophages in reactive follicles of lymph node (fig 3), as well as interfollicular, and medullary sinus macrophages. The antibody reacted with interfollicular tingible body macrophages and intraepithelial indeterminate dendritic cells (fig 4) in tonsil, in phagocytotic cells lining splenic cords, as well as in follicular macrophages of the white pulp (fig 5). EBM/11 also reacted with macrophages in the lamina propria of the stomach, small and large bowel (fig 6) and with villous macrophages (Hofbauer cells) in the placenta (fig 7).

Peripheral blood monocytes, bone marrow mononuclear cells (presumptive macrophages), and osteoclasts strongly reacted with $\mathrm{EBM} / 11$; megakaryocytes stained weakly (fig 8).

Connective tissue histiocytes in thyroid, kidney, dermis, muscularis propria of bowel, prostate, myocardium, ovary, pancreas, testis, breast and cervix were stained with $E B M / 11$. In brain, however, EBM/11 stained only perivascular macrophages. It did not stain microglia, interdigitating reticulum cells, or Langerhans' cells as it did in frozen sections.

Epitheloid and multinucleated giant cells in sarcoidosis, tuberculosis, and giant cells thyroiditis (fig 9) are strongly reactive with EBM/11: foamy macrophages in granulomatous mastitis are weakly positive (data not shown).

There was no staining of lymphocytes, plasma cells, plasmacytoid $T$ cells, polymorphs, red cells, endothelium, or epithelial cells in any organ screened. There was, however, weak staining of renal tubular epithelium similar to that observed in fresh frozen sections.

There was no staining in serial sections from the same biopsy specimens used for EBM/11 with the negative controls-that is, normal culture medium or JMB1. Epithelial monoclonal markers (known to react on paraffin wax sections) selectively stained epithelial cells.

These staining patterns with EBM/11 were observed in about $90 \%$ of archival tissues tested. The other $10 \%$ showed weak or patchy specific staining. Therefore, the effects of fixation conditions on $\mathrm{EBM} / 11$ reactivity were 
Figure 1 Granular cytoplasmic staining of alveolar macrophages by EBM/11. Some macrophages also contain ingested carbon particles (arrow).

Figure $2 \quad E B M / 11$ positive Kupffer cells of liver.

Figure 3 Staining of subcapsular, mantle zone, paracortical and tingible body macrophages of lymph node.

Figure 4 Intraepithelial indeterminate dendritic cells and germinal centre macrophages of tonsil are $E B M / 11$ positive.

Figure 5 Phagocytic cells of splenic cords of Bilroth and tingible body macrophages of white pulp are reactive with $E B M$ 11.

Figure 6 Staining of macrophages of the lamina propria of large bowel by $E B M / 11$.

Figure 7 Macrophages (Hoffbauer cells) within villi of placenta are strongly $E B M / 11$ positive.

Figure 8 Bone marrow macrophages and osteoclasts (arrow) are EBM/11 positive.

Figure 9 Strongly staining multinucleated giant cells by $E B M / 11$ in de Quervin's thyroiditis.
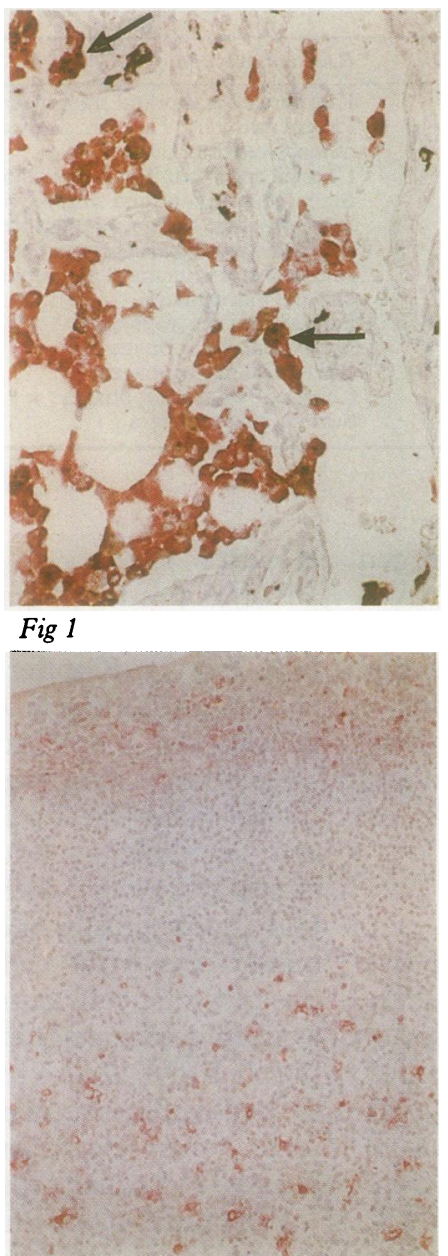

Fig 4

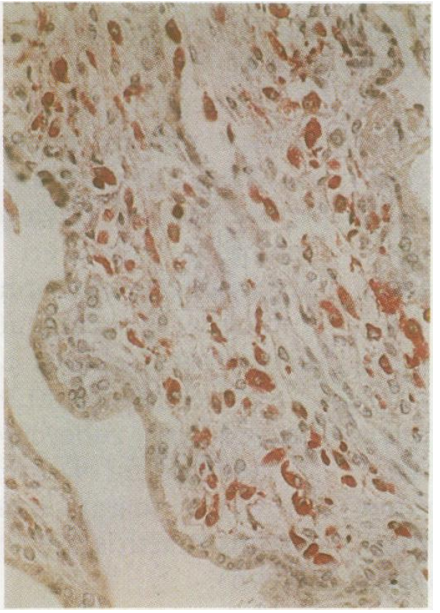

Fig 7

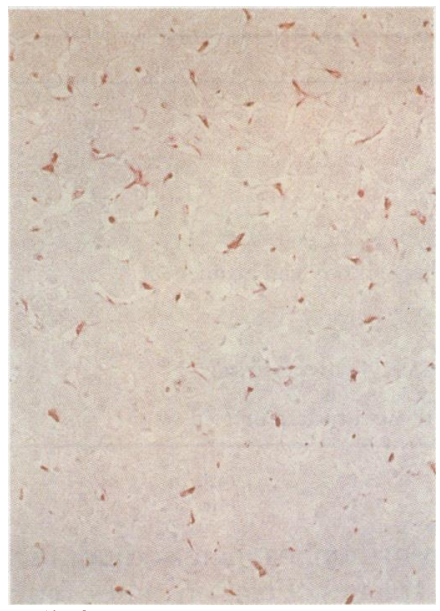

Fig 2

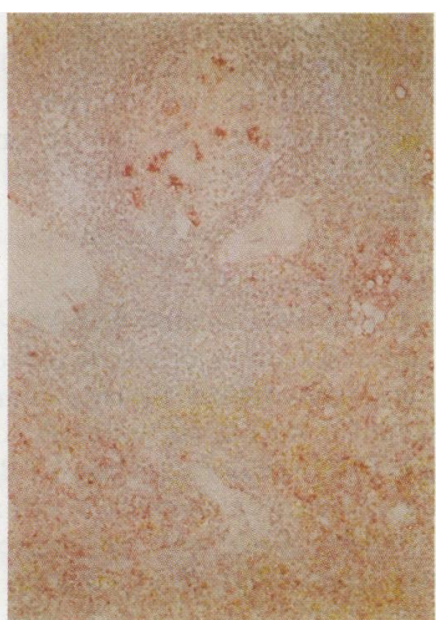

Fig 5

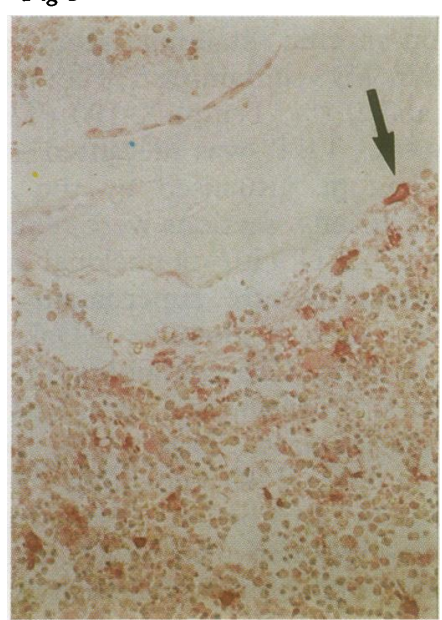

Fig 8

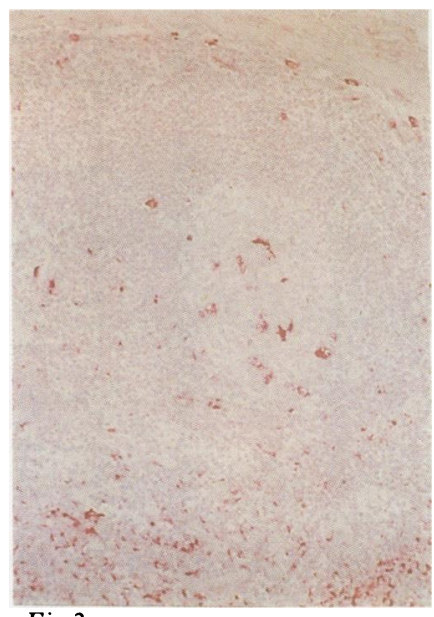

Fig 3

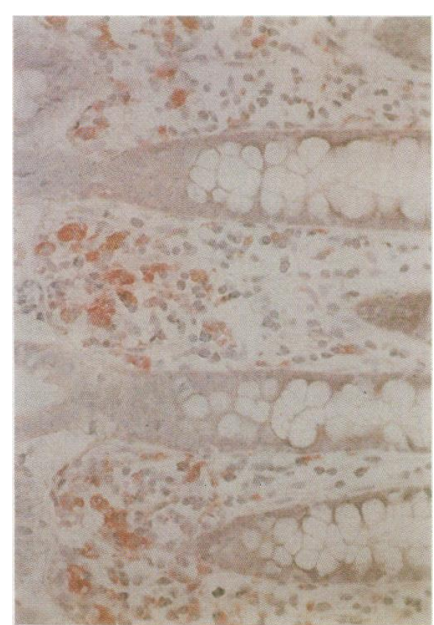

Fig 6

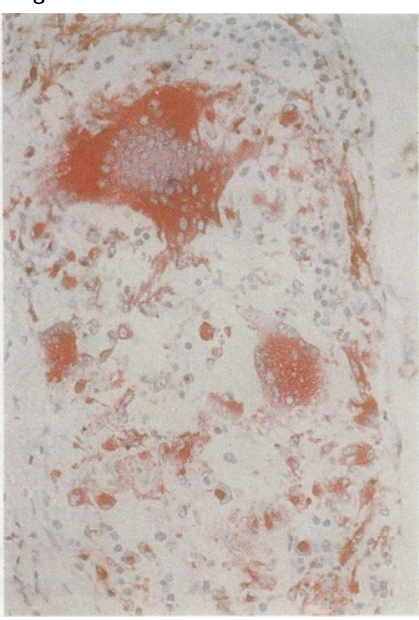

Fig 9 investigated on adjacent blocks of necropsy tissues. Specific staining of mononuclear phagocyte system cells was observed in all tissues fixed for a minimum of 48 hours in solutions of unbuffered formol-saline, neutral and alkaline ( $\mathrm{pH} \mathrm{8.4)} \mathrm{buffered} \mathrm{formaldehyde.}$ There was no change in staining intensity when tissues were fixed for up to seven days (but see below). Tissues fixed for 24 to 48 hours showed staining of mononuclear phagocyte system cells only in the $1 \mathrm{~mm}$ thick outer edge of each block. In the 48 hour blocks, there was patchy staining in the block centres, especially around medium and large vessels. This was particularly noted in organs where there was vascular dilatation and congestion, such as in congestive cardiac failure in liver, and frequently in spleen. There was no staining in most tissues (irrespective of blood content) fixed for less than 24 hours. Weak or patchy or no staining was observed in partially auiolysed tissue, or in tissues stored in formaldehyde fixatives for one year.

Tissues fixed in acetic acid/formol-saline ( $\mathrm{pH} 2)$, regardless of fixation time, did not react with $\mathrm{EBM} / 11$.

\section{Discussion}

In about $90 \%$ of archival paraffin wax embedded surgical biopsy specimens (stored for 10 
Table 2 Discrepancies between EBM/11 reactivity on paraffin wax and frozen sections

\begin{tabular}{lll}
\hline Tissue & $\begin{array}{l}\text { Paraffin wax } \\
\text { section }\end{array}$ & Frozen section \\
\hline Langerhans' cells of skin & - & + \\
Interdigitating reticulum cells & - & + \\
$\begin{array}{l}\text { Digitating reticulum cells } \\
\text { Indeterminate reticulum cells }\end{array}$ & - & + \\
$\quad$ of tonsilar epithelium & + & $? \star$ \\
Microglia & - & + \\
ॠThis was not examined in reference. $^{6}$ &
\end{tabular}

years) $E B M / 11$ reacts with most cells of the mononuclear phagocyte system as it does in frozen sections; the exceptions are shown in table 2. This indicates that the cytoplasmic epitope is not destroyed or irretrievably crosslinked by routine formalin fixation and paraffin wax embedding. The controlled fixation experiments on necropsy blocks show that the optimal fixation for this epitope in formaldehyde solutions is $24-48$ hours. Otherwise, it is degraded, changed, or lost during subsequent paraffin chemical processing to paraffin wax. The weak and patchy staining with EBM/11 in about $10 \%$ of archival samples is probably therefore due to "under-fixation". The lack of staining in specimens stored in formalin for one year may be due to high levels of aldehyde cross-linking. The practical and clinical implications of these results are that EBM/11 can be used for the positive identification of mononuclear phagocyte system cells in archival surgical biopsy specimens, but that weak or patchy reactivity should not be interpreted, in absolute terms, as excluding a particular cell from the mononuclear phagocyte system.

Unmasking of "well fixed" EBM/11 epitopes was only attained by limited proteolysis with type XIV protease which has broad substrate specificity; trypsin, pepsin, protease $\mathrm{K}$ and type XXIV protease were ineffective (data not shown). The lack of staining of mononuclear phagocyte system cells with negative controls (irrelevant monoclonal antibody JMB1, or with normal culture medium) underline the selective unmasking of the EBM/11 epitope by this enzyme under these conditions.

The production of $E B M / 11$ and the immunobiochemical characterisation of the epitope it recognises have been reported, ${ }^{6}$ but the function of the molecules containing the epitope is unknown. It is interesting, however, that some mononuclear phagocyte system cells involved in active phagocytosis, such as fat ladden foamy macrophages, stain only weakly with EBM/11. On the other hand, "terminally differentiated" tissue macrophages, such as epitheloid macrophages and multinucleated giant cells (presumptive macrophages polykaryons), react strongly and consistently (fig 9). Recent evidence suggests that epitheloid macrophages and multinucleated giant cells are probably non-phagocytic but have high synthesis or secretory activities. ${ }^{16}$ This raises the possibility that the regulation of the molecules containing the EBM/11 epitope may be associated with increased synthesis or secretory functions and not active phagocytosis. This idea is supported by the preliminary localisation of this determinant to smooth or rough endoplasmic reticulum. ${ }^{6}$

EBM/11, together with other pan-macrophage markers such as $\mathrm{Ki}-\mathrm{M} 7,{ }^{1} \mathrm{Y} 1 / 82 \mathrm{~A},{ }^{17} \mathrm{Ki}$ M6, ${ }^{18}$ antibody $24^{19}$ and $\mathrm{Y} 2 / 131$ have been assigned to the CD68 group..$^{20}$ Of these, EBM/ 11 may have more precise diagnostic importance because of its high cellular specificity for mononuclear phagocyte system cells in routine formalin paraffin wax sections. The other antibodies in the CD68 group react with cells outside the mononuclear phagocyte system. For example, $\mathrm{Ki}-\mathrm{M} 7$ inconsistently stains tissue macrophages and stains marginal zone $B$ cells and some B cell lymphomas in paraffin wax sections. ${ }^{1}$ EBM/11 and KP1 (which has been assigned to the CD68 group by the Fourth Workshop on Leucocyte Differentiation Antigens ${ }^{21}$ ), have similar reactions in paraffin wax sections except that KP1 labels immature or mature cells of other subgroups within the myelomonocytic linage (myeloid precursors, granulocytes) and plasmacytoid T-cells. ${ }^{2}$ Therefore, EBM/11 clearly differentiates between granulocyte and monocyte macrophage cell lines, although both of these are considered to differentiate from a common committed precursor, the myelomonoblast. It is therefore tempting to postulate that the EBM/11 epitope is acquired by monocytes only during or after their differentiation from the committed precursor.

Other monoclonal antibodies which have been used for macrophage identification in paraffin wax sections include MAC387 and VIM-13 (CD14): MAC387, however, strongly stains granulocytes and squamous epithelium. ${ }^{3}$ VIM-13, on the other hand, although relatively specific for monocyte macrophages in fresh frozen sections, stains germinal centre $B$ cells in formalin fixed, paraffin wax sections after pronase predigestion. ${ }^{22}$

In conclusion, EBM/11 has high cellular specificity for mononuclear phagocyte system cells in archival formalin fixed paraffin wax embedded tissues; special fixatives or special processing are not necessary. Routine neutral formaldehyde fixation for 48 hours is sufficient. This may facilitate retrospective immunohistopathological analysis of archival biopsy specimens and may lead to a fuller understanding of macrophages function in disease. Furthermore, these results will raise the possibility that some other monoclonal antibodies, thought to exclusively react in frozen sections or in tissues fixed in uncommon fixatives, may also be reactive in routinely processed formalin fixed paraffin wax biopsy specimens after controlled digestion with an appropriate enzyme.

This work was supported by grants from the Cancer Research Campaign, UK. (J O'D McGee). GING was a WHO fellow and SPM was a Medical Research Council Student.

1 Kreipe H, Radzun HJ, Parwaresch MR, et al. Ki-M monoclonal antibody specific for myelomonocytic cel inage and macrophages in humans.J Histochem Cytochem 1987;35:1117-26.

2 Pulford KAF, Rigney EM, Micklem KJ, et al. KP1: a new 
monoclonal antibody that detects a monocyte/macrophage associated antigen in routinely processed tissue sections. $J$ Clin Pathol 1989;42:414-21.

3 Flavell DJ, Jene DB, Wright DH. Identification of tissue histiocytes on paraffin sections by a new monoclonal antibody. $J$ Histochem Cytochem 1987;35:1217-26.

4 Davey FR, Gatter KC, Ralfkiar E, et al. Immunophenotyping of non-Hodgkin's lymphomas using a panel of antibodies on paraffin embedded tissues. Am J Pathol 1987;129:54-63.

5 Poppema S, Hollema $\mathrm{H}$, Visser L, Vos H. Monoclonal antibodies (MT1, MT2, MB1, MB2 and MB3) reactive antibodies (MT1, MT2, MB1, MB2 and MB3) reactive
with leucocyte subsets in paraffin-embedded tissue secwith leucocyte subsets in paraffin-en
tions. $A m$ J Pathol 1987;127:418-29.

6 Kelly PM, Bliss E, Morton JA, Burns J, McGee JO'D. Monoclonal antibody EBM/11: high cellular specificity for human macrophages. J Clin Pathol 1988;41:510-5.

7 Athanasou NA, Bliss E, Gatter KC, Heryet A, Woods CG McGee JO'D. An immunohistochemical study of giantcell tumour of bone: evidence of an osteoclast origin of the giant cells. J Pathol 1985;147:153-8.

8 Athanasou NA, Heryet A, Quinn J, Gatter KC, Mason DY, McGee JO'D. Osteoclasts contain macrophages and megakaryocytes antigens. J Pathol 1986;150:239-46.

9 Esiri MM, McGee JO'D. Monoclonal antibody of macrophages (EBM/11) labels macrophages and microglial cells

10 Franklin WA, Mason DY, Pulford $\mathrm{K}$, et al. Immunohistological analysis of human mononuclear phagocytes and dendritic cells by using monoclonal antibodies. $L a b$ Invest 1986;54:322-35.

11 Kelly PM, Davison RS, Bliss E, McGee JO'D. Macrophages in human breast disease: a quantitative immunohistochemical study. Br J Cancer 1988;57:174-7.

12 Cordell JL, Falani B, Erber WN, et al. Immunoenzymatic labelling of monoclonal antibodies using immune complex of alkaline phosphatase and monoclonal anti-alkaline phosphatase (APAAP complex). J Histochem Cytochem
1984;32:219-29.

13 Gatter KC, Falini B, Mason DY. The use of monoclonal antibodies in histopathological diagnosis. In: Anthony $\mathrm{P}$, MacSween RNM, eds. Recent advances in histopathology. No 12. Edinburgh: Churchill-Livingstone, 1984:35-67.

14 Heyderman E. Immunoperoxidase technique in histopathology: application methods and control. J Clin Pathol 1978;32:972-8.

15 McGee JO'D, Morton JA, Barbatis C, et al. Monoclonal antibodies to Mallory bodies/intermediate filaments and HLA (Class 1) antigens in human liver disease. In: McMichael AJ, Fabre JW, eds. Monoclonal antibodies in clinical medicine. London: Academic Press, 1982.

16 Kreipe H, Radzun HJ, Rudolph P, et al. Multinucleated giant cells generated in vitro. Terminally differentiated macrophages with down-regulated c-fms expression. $A m$ J Pathol 1988;130:232-43.

17 Davey FR, Cordell JL, Erber WN, et al. A monoclonal antibody (Y1/82A) with specificity towards peripheral blood monocytes and tissue macrophages. J Clin Patho 1988;41:753-8.

18 Parwaresch MR, Radzun HJ, Kreipe H, et al. Monocyte/ macrophage-reactive monoclonal antibody $\mathrm{Ki}-\mathrm{M} 6$ recognises an intracytoplasmic antigen. $A m \mathrm{~J}$ Pathol 1986;125:141-51.

19 Hogg N, Selvendran Y. An anti-human monocyte/macrophage monoclonal antibody reacting most strongly with macrophages on lymphoid tissue. Cell Immunol 1985:92:247-53.

$20 \mathrm{Hogg}$ N, Horton MA. Myeloid antigens: new and previously defined clusters. In: McMichael AN, ed. Leucocyte typin III. Oxford: Oxford University Press, 1987:576-629. 21 Micklem K, Rigney E, Cordell J, et al. A human macromonoclonal antibodies. Br J Haematol 1989;73:6-11.

22 Magyarti T. Possibility of using monoclonal antibodies on formalin-paraffin sections. Morphol Igazsagugyi Orv Sz. 1988;8:247-54. 